\title{
Development in vitro and pathogenicity of an erythromycin-resistant strain of Renibacterium salmoninarum, the causative agent of bacterial kidney disease in salmonids
}

\author{
G. R. Bell, G. S. Traxler, C. Dworschak \\ Department of Fisheries and Oceans, Fisheries Research Branch, Pacific Biological Station, Nanaimo, British Columbia, \\ Canada V9R 5K6
}

\begin{abstract}
This study was prompted by concern that the widespread use of erythromycin (EY) for prophylactic treatment of kidney disease of salmonids caused by Renibacterium salmoninarum (Rs) could lead to the development of antibiotic-resistant strains of the pathogen. From a British Columbia strain of Rs sensitive to EY (minimum inhibitory concentration of ca $0.25 \mu \mathrm{g} \mathrm{EY} \mathrm{ml}^{-1}$ ) a highly resistant culture was developed in vitro by inoculating cells growing in the presence of $0.1 \mu \mathrm{g} \mathrm{EY} \mathrm{ml}^{-1}$ onto media containing increasingly higher concentrations of antibiotic, up to $500 \mu \mathrm{g} \mathrm{EY} \mathrm{ml} \mathrm{m}^{-1}$. The high level of resistance was maintained for at least 6 passages on EY-free medium but declined on further passaging. The resistant strain was of lower virulence for sockeye salmon Oncorhynchus nerka than the parent strain. Attenuation of the EY-resistant strain appeared to be attributable more to serial passage on culture media than to an effect of the antibiotic. Implications of these findings are discussed in relation to fish culture practices.
\end{abstract}

\section{INTRODUCTION}

Following reports of Wolf \& Dunbar (1959), Klontz (1973), Groman \& Klontz (1983), Austin (1985a), and Bullock \& Leek (1986), the broad spectrum, macrolide antibiotic erythromycin has been widely used in an effort to prevent or control the spread of kidney disease of salmonids caused by Renibacterium salmoninarum. Concern that extensive therapeutic use of this antibiotic could lead to the generation of antibiotic-resistant strains of $R$. salmoninarum stimulated the investigation reported here. Development in vitro of erythromycin resistance in a British Columbia (BC) isolate of $R$. salmoninarum and some physiologic and pathologic properties of the resistant strain are described.

\section{MATERIALS AND METHODS}

Bacterial cultures. A strain of Renibacterium salmoninarum (our stock 384) used by Bell et al. (1984) was cultured to develop erythromycin (EY) resistance. To our knowledge this strain had not been exposed previously to EY. This parent strain will be designated Rs; RsR will refer to the derived EY-resistant strain, and RsP to the parent strain that had been passaged on EY. free medium 12 times (starting from the frozen stock of Rs) to simulate passages used to develop RsR

Culture media. Our Rs strain, stored at $-85^{\circ} \mathrm{C}$, was routinely cultured at $15^{\circ} \mathrm{C}$ on $\mathrm{KDM} 2$ agar (Evelyn 1977 ) but containing only $5 \%$ foetal bovine serum. This medium, here designated $\mathrm{K} 5$, was also used as a base to which filter-sterilized erythromycin (Sigma No. E6376) was added aseptically just before pouring the cooled liquid agar. Concentrations of antibiotic are reported as active ingredient.

Quantitative evaluation of growth. The drop-plating technique of Miles \& Misra (1938) was used for enumeration of Rs on K5, and counts were based on the mean number of colonies from 5 or 7 replicate $25 \mu \mathrm{l}$ drops. Colonies were counted under a stereomicroscope. In addition, a quantitative estimate of biomass was obtained using the following procedure. Five replicate plugs of agar with growth from each $25 \mu \mathrm{l}$ drop were removed with a cork borer. Each plug was placed in a test tube and agitated in $10 \mathrm{ml}$ of $0.85 \% \mathrm{NaCl}$ 
containing $0.1 \%$ formalin to prevent further growth When growth had been removed and the agar had settled, the absorbance of the supernatant was read in a 'Spectronic 20' (Bausch and Lomb) spectrophotometer at $540 \mathrm{~nm}$

Stability of erythromycin in K5. Erythromycin concentrations were determined using the method described by Evelyn et al. (1986), except that test solutions were added to stainless steel cylinders placed on the bioassay agar

The stability of EY under our conditions of media preparation and incubation was determined using liquid rather than solid $\mathrm{K} 5$ for practical reasons. Autoclaved medium was cooled to $46^{\circ} \mathrm{C}$; serum and filtersterilized EY were added to provide aliquots containing $0.125,0.25$, and $0.5 \mu \mathrm{g} \mathrm{EY} \mathrm{ml}^{-1}$. These hquidd àiquuts were then treated comparably to solid K5. Samples for assay were removed immediately and at intervals up to $12 \mathrm{~d}$ of incubation at $15^{\circ} \mathrm{C}$. Samples were stored at $-85^{\circ} \mathrm{C}$ and assayed as a group for EY concentration.

Development of resistance to erythromycin. Resistance was developed by exposing Rs to a series of increasing concentrations of EX. Cells surviving at the highest levels of antibiotic were then plated on even higher levels. Initially, $25 \mu \mathrm{l}$ suspensions of Rs $\left(2 \times 10^{6}\right.$ cfu [colony forming units] $\mathrm{ml}^{-1}$ ) were dropped onto $\mathrm{K} 5$

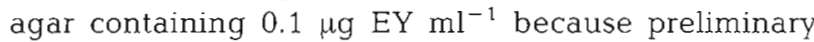
studies showed that the MIC (Minimum Inhibitory Concentration) was between 0.25 and $0.5 \mu \mathrm{g} \mathrm{EY} \mathrm{ml}^{-1}$ Growth was then suspended in sterile tap water and drop-plated on K5 (control) and on K5 containing 0.25 $\mu \mathrm{g} \mathrm{EY} \mathrm{ml} \mathrm{m}^{-1}$. The procedure was repeated using 1.0, 1.5, 4, 10, 25, 100 and, finally, $500 \mu \mathrm{g} \mathrm{EY} \mathrm{ml}{ }^{-1}$, usually after 14 to $18 \mathrm{~d}$ incubation. Intermediate concentrations of EY were also tested at each transfer but inocula were taken from media containing the above levels of EY, the highest tested at each transfer.

Stability of resistance to erythromycin. In order to test the stability of resistance to EY, Strain RsR was serially transferred on antibiotic-free $K 5$ medium. At each transfer the cells were also plated on media containing $0.5,300$, and $500 \mu \mathrm{g} \mathrm{EY} \mathrm{ml}{ }^{-1}$. The time between transfers of RsR on antibiotic-free medium ranged from 7 to $18 \mathrm{~d}$. Subcultures on antibiotic-containing media were incubated up to a maximum of $30 \mathrm{~d}$ before being discarded.

Pathogenicity tests. Sockeye salmon Oncorhynchus nerka were obtained in 1982 as surface-disinfected eggs from Weaver Creek, $\mathrm{BC}$, reared in ground water, and fed Oregon Moist pellets (OMP) (Moore-Clark Co.) under the normal daylight cycle at the Rosewall Creek, Vancouver Island, rearing facility. In July 1984 the fish were brought to the Pacific Biological Station for experimentation where rearing continued as before but in dechlorinated Nanaimo City water. Chemical characteristics of both rearing waters have been described by Bell et al. (1984).

Two experiments were conducted to compare the pathogenicity of Rs, RsR, and RsP. In the first experiment, 50 to $70 \mathrm{~g}$ anaesthetized (75 ppm MS222) sockeye salmon were each inoculated intraperitoneally (i.p.) with $0.1 \mathrm{ml}$ of aseptically prepared dilutions of viable cells in physiological saline. Each of 3 groups of $10 \mathrm{fish}$ was given in the order of $10^{6}, 10^{4}$ or $10^{2}$ bacteria (Rs or RsR) fish ${ }^{-1}$, respectively. Fish were fin-clipped to identify the dosage given and the Rs- and RsR-inoculated fish were reared in 2 separate $200 \mathrm{l}$ fibreglass tanks with a flow rate of ca $151 \mathrm{~min}^{-1}$. Control fish (10) were injected similarly with sterile physiological saline and placed in a separate tank. Fish were fed to satiation 5 d per week and reared in fresh water, the temperature regime of which is included in Fig. 1. A similar protocol was followed in the second experiment.

In the second experiment the pathogenicity of RsR was also compared to that of the parent strain that had been passaged on K5, i.e. to Strain RsP. In both experiments, Rs and RsR inocula were stored at $-85^{\circ} \mathrm{C}$ until needed, rather than being maintained by passage on fresh media. Unless otherwise noted, rearing densities and tank dimensions were similar for each strain of inoculum tested. The same stock of sockeye salmon (new weight range 130 to $160 \mathrm{~g}$ ) as used in the first experiment was inoculated.

Confirmation of BKD. Kidney tissue from dead or moribund fish was routinely examined for typical lesions (Fryer \& Sanders 1981) and plated aseptically on Tryptic Soy Agar (TSA, Difco) and on K5. Smears for microscopic examination were also made. Plates were incubated for 6 wh at $15^{\circ} \mathrm{C}$ before being discarded. Fish were considered to have confirmed BKD if there was little or no growth on TSA but typical growth of Rs on K5. If, as rarely happened, there was no growth of Rs on $\mathrm{K} 5$ despite the presence of typical lesions and numerous characteristic Rs cells in kidney smears, the fish were also considered to have died of BKD.

Viable counts of Rs in the kidney. Enumeration of Rs in the kidney was done by first removing the entire kidney aseptically. The tissue, without its covering membrane, was weighed, diluted $1: 1(\mathrm{w} / \mathrm{v})$ with sterile physiological saline and thoroughly blended in an iced, sterile, glass homogenizer. Serial 10-fold dilutions in sterile saline were prepared from which $25 \mu \mathrm{l}$ aliquots were drop-plated as previously described. Numbers are reported as cfu (particularly because cells may have been aggregated) per gram wet weight of kidney, and were determined by averaging colony counts from 5 replicate drops.

Haematocrits. Haematocrits were determined using heparinized capiliary tubes spun for $3 \mathrm{~min}$ in a ClayAdams microhaematocrit centrifuge. 


\section{RESULTS AND DISCUSSION}

\section{Stability of erythromycin in K5}

Erythromycin appeared to be stable under our conditions as evidenced by the fact that zones of inhibition were constant ( $\pm 1 \mathrm{~mm}$ ) from replicate samples taken throughout the $12 \mathrm{~d}$ incubation period. Further, the weighed amount of EY added to the test medium was quantitatively confirmed by the bacterial assay method (data not shown). Medium without added EY gave no zone of inhibition. We therefore concluded that cells inoculated onto antibiotic-containing media were exposed to the actual amount of EY indicated.

\section{Development of resistance to erythromycin}

Our strain of Rs, the initial MIC value of which was determined to be ca $0.25 \mu \mathrm{g} \mathrm{EY} \mathrm{ml}{ }^{-1}$, eventually grew in the presence of $500 \mu \mathrm{g} \mathrm{EY} \mathrm{ml}^{-1}$ by culturing it with stepwise increases in the level of antibiotic. As measured by our quantitative technique, growth on EYcontaining media was less than half that on K5 alone until a range of 16 to $30 \mu \mathrm{g} \mathrm{EY} \mathrm{ml} \mathrm{m}^{-1}$ was reached. In this range, growth was equal to but not significantly greater than that on K5 ( $p>0.05$ by 1 -way ANOVA). At concentrations of $E Y>30 \mu \mathrm{g} \mathrm{ml}^{-1}$, growth again declined significantly $(p<0.05)$ compared to that on K5 alone (data not shown).

Based on the incremental levels of EY used to develop the resistant strain of Rs, it is evident that cells were able to grow with 3 - to 5 -fold increases in concentration of the antibiotic. It is not known if the cells could have withstood even greater increases because each of the 7 concentrations of EY $(0.25,1,1.5,4,10,25$, and $100 \mu \mathrm{g} \mathrm{ml}^{-1}$ ) used to develop resistance was the highest tested at each transfer. In other words, there might have been a concentration of EY at which cells were 'switched on' and became remarkably more resistant, as occurred with certain staphylococci (Weisblum \& Demohn 1969). If so, this concentration was not determined for Rs.

\section{Growth of Rs and RsR on antibiotic media and stability of resistance}

The results shown in Part A of Table 1 again confirm that the MIC of EY for Rs is about $0.25 \mu \mathrm{g} \mathrm{ml}^{-1}$ and also show what portion of the inocula grew at lower levels of the antibiotic. (Although these percentages are based on a broad range of plate counts, they could be useful for estimating the fraction of a population of naive, i.e. EY-susceptible, Rs that might proliferate in the pres- ence of various concentrations of EY.) The portion of the population that failed to grow might either have been inhibited or killed, that is, all of the initial inoculum might have survived but only some grew. Whether EY is bacteristatic or bactericidal depends upon many factors, the most important of which is concentration of the antibiotic. The usual prophylactic dosage is about $10 \mathrm{mg} \mathrm{EY} \mathrm{kg}{ }^{-1}$ fish body weight (Hastein 1984). Approximating this dosage to $10 \mathrm{mg} \mathrm{l}^{-1}$ and assuming uniform distribution, the concentration would be equivalent to $10 \mu \mathrm{g} \mathrm{ml}^{-1}$, initially well above the MIC, before physiological clearance.

In contrast to our results, Austin (1985a) found that all 40 of his test strains of Rs streaked on KDM 2 failed to grow at a concentration of EY phosphate as low as $0.05 \mu \mathrm{g} \mathrm{m} \mathrm{m}^{-1}$. Austin's strains might have been more susceptible than ours but possibly his inocula were too low or his incubation times too short to allow any resistant cells to form visible growth.

As can be seen from Part B of Table 1, growth of RsR was not inhibited by any concentration of EY from 0 to $500 \mu \mathrm{g} \mathrm{ml}^{-1}$. (Increased survival in the presence of $E Y$ is probably spurious.) From Part $\mathrm{C}$ of Table 1 it can be seen that there was no significant $(p>0.05)$ decline in growth at any level of EY even after 6 serial passages on EY-free medium. Despite the absence of selective pressure from EY in vitro, it was not until after 3 additional passages that resistance was rather abruptly reduced to near the original level of sensitivity (data not shown). Following the 10th passage of RsR on EYfree medium, growth in the presence of $0.5 \mu \mathrm{g} \mathrm{EY} \mathrm{ml}^{-1}$ was very scant compared to that from the same inoculum on $\mathrm{K} 5$. On the 11 th passage the former EYresistant strain failed to grow at the aforementioned level of EY but grew readily on antibiotic-free medium. Controls of the parent EY-sensitive strain grew well on K5 but always failed to grow in the presence of $0.5 \mu \mathrm{g}$ $\mathrm{EY} \mathrm{ml}^{-1}$ unless extremely heavy inocula and long incubation times were used.

Therapeutically, the development in vitro of resistant Rs and the stability of this property are disconcerting but it remains to be seen if either of these events can occur in vivo. Further, pathogenicity tests reported herein suggest that RsR would probably not readily survive in the host, although survival might be quite different if resistant Rs were formed in vivo.

\section{Mechanism of resistance to erythromycin}

Resistance to antimicrobials may be associated with constitutive or inducible factors, chromosomal mutations, or with DNA replicons in episomes or plasmids. As Davies \& Smith (1978) pointed out, there are a number of possible mechanisms to explain antimicro- 
Table 1. Renibacterium salmoninarum. Survival of Rs 384 on first exposure to erythromycin, after developing resistance (RsR), and after the resistant culture had been subcultured on antibiotic-free medium

\begin{tabular}{|c|c|c|c|c|}
\hline $\begin{array}{l}\text { Erythromycin } \\
\quad\left(\mu \mathrm{gl}^{-1}\right)\end{array}$ & $\begin{array}{l}\text { Dilution of } \\
\text { inoculum }\end{array}$ & $\begin{array}{l}\text { Mean cfu } 0.025 \mathrm{ml}^{-1} \\
\quad(n=7) \text { [range] }\end{array}$ & cfu ml $\mathrm{ml}^{-1}$ & $\begin{array}{l}\text { Calculated } \\
\% \text { survivors }\end{array}$ \\
\hline \multicolumn{5}{|l|}{ (A) First exposure (Rs) } \\
\hline $0(\mathrm{~K} 5)$ & $10^{-6}$ & $\begin{array}{l}73 \\
{[65-76]}\end{array}$ & $2.92 \times 10^{9}$ & $100^{\mathrm{a}}$ \\
\hline 0.025 & $10^{-6}$ & $\begin{array}{l}55 \\
{[49-61]}\end{array}$ & $2.20 \times 10^{9}$ & 75 \\
\hline 0.05 & $10^{-6}$ & $\begin{array}{l}40 \\
{[36-48]}\end{array}$ & $1.60 \times 10^{9}$ & $55(79)$ \\
\hline 0.1 & $10^{-6}$ & $\begin{array}{l}31 \\
{[29-35]}\end{array}$ & $1.24 \times 10^{9}$ & $42(33)$ \\
\hline 0.25 & $10^{-4}$ & $\begin{array}{l}41 \\
{[38-50]}\end{array}$ & $1.64 \times 10^{7}$ & $0.56(1)$ \\
\hline 0.5 & $10^{-4}$ & 0 & 0 & $0(0)$ \\
\hline \multicolumn{5}{|c|}{ (B) Resistant culture (RsR) } \\
\hline $0(\mathrm{~K} 5)$ & $10^{-6}$ & $\begin{array}{l}95 \\
{[90-105]}\end{array}$ & $3.80 \times 10^{9}$ & $100^{a}$ \\
\hline 100 & $10^{-6}$ & $\begin{array}{l}101 \\
{[89-107]}\end{array}$ & $4.04 \times 10^{9}$ & 106 \\
\hline 200 & $10^{-6}$ & $\begin{array}{l}101 \\
{[87-116]}\end{array}$ & $4.04 \times 10^{9}$ & 106 \\
\hline 300 & $10^{-6}$ & $\begin{array}{l}97 \\
{[84-107]}\end{array}$ & $3.88 \times 10^{9}$ & 102 \\
\hline 400 & $10^{-6}$ & $\begin{array}{l}100 \\
{[84-121]}\end{array}$ & $4.0 \times 10^{9}$ & 105 \\
\hline 500 & $10^{-6}$ & {$[81-117]$} & $3.92 \times 10^{9}$ & 103 \\
\hline \multicolumn{5}{|c|}{ (C) Resistant culture (RsR) from erythromycin-free medium ${ }^{\text {b }}$} \\
\hline $0(\mathrm{~K} 5)$ & $10^{-6}$ & $\begin{array}{l}336 \\
{[321-361]}\end{array}$ & $1.34 \times 10^{10}$ & $100^{\alpha}$ \\
\hline 100 & $10^{-6}$ & $\begin{array}{l}315 \\
{[264-351]}\end{array}$ & $1.26 \times 10^{10}$ & 94 \\
\hline 200 & $10^{-6}$ & $\begin{array}{l}311 \\
{[279-338 \mid}\end{array}$ & $1.24 \times 10^{10}$ & 93 \\
\hline 300 & $10^{-6}$ & $\begin{array}{l}330 \\
{[310-352]}\end{array}$ & $1.32 \times 10^{10}$ & 99 \\
\hline 400 & $10^{-6}$ & $\begin{array}{l}304 \\
{[264-337]}\end{array}$ & $1.22 \times 10^{10}$ & 91 \\
\hline 500 & $10^{-6}$ & $\begin{array}{l}302 \\
{[259-362]}\end{array}$ & $1.21 \times 10^{10}$ & 90 \\
\hline \multicolumn{5}{|c|}{$\begin{array}{l}\text { arbitrarily designated to be } 100 \% \text {. Numbers in parentheses are from a similar experiment in which the inoculum contained } \\
8 \times 10^{7} \mathrm{cfu} \mathrm{\textrm {ml } ^ { - 1 }} \\
\text { b Passaged } 6 \text { times on erythromycin-free medium (K5) }\end{array}$} \\
\hline
\end{tabular}

bial resistance. Briefly, some of these are: blockage of entry of the drug into the cell; altered affinity of the target site for the drug; inactivation of the drug; bypassing the blocked pathway; reducing the cell's dependence on the blocked pathway; saturating or 'titrating out' the drug; producing an inhibitor of the inhibiting drug.

The macrolide EY is one of several classes of antibiotics listed by Weisblum \& Demohn (1969) that inhibit the activity of the $50 \mathrm{~S}$ ribosome subunit. Resistance to EY and other macrolides appears to be associated with mutational (Tanaka et al. 1968) or plasmid-mediated
(Weisblum et al. 1971) blockage (e.g. methylation) of the binding site(s) on the 23S RNA, the latter phenomenon occurring in streptococci and staphylococci. It is noteworthy that EY-resistant cells usually also show cross-resistance to other macrolide antibiotics. However, Weisblum \& Demohn (1969) reported that certain EY-resistant mutants of Staphylococcus aureus had the unusual property of sensitivity to other macrolides. Moreover, when these mutants were exposed to

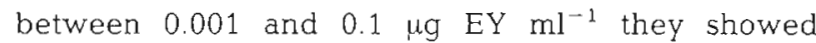
induced resistance to certain other macrolides, lincosaminides, and the streptogramin-B group. In this 
case, EY was said to have 'antagonized' the action of other antibiotics that also act on the $50 \mathrm{~S}$ ribosome subunits. It would be interesting to know if our RsR showed any of the above properties but we have not tested cross-resistance to any other macrolides, nor have we tested directly or indirectly for plasmids. Regarding plasmids, it is noteworthy that Toranzo et al. (1983) were unable to detect plasmid DNA in a strain of Renibacterium salmoninarum used in a survey of plasmids in bacterial fish pathogens.

In summary, the mechanism of EY resistance developed in our strain of Rs is unknown.

\section{Pathogenicity of RsR}

Experiment 1

Although i.p. inoculations of Rs into sockeye salmon smolts caused mortality in patterns like those that had been demonstrated in earlier work (Bell et al. 1984) (Fig. 1), inoculation of comparable numbers of RsR into other groups of smolts did not result in any mortality during the $170 \mathrm{~d}$ incubation period. (There was also no mortality of saline-injected control smolts.) These results suggest that RsR was either avirulent, or of low virulence compared to Rs. At the termination of the experiment the RsR-inoculated fish appeared grossly healthy and had mean haematocrits of $41 \% \pm 3$ (standard deviation, SD) compared to saline-injected controls with a mean haematocrit of $47 \% \pm 1.4 \mathrm{SD}$. No bacteria could be cultured from the kidneys of RsRinoculated smolts using any of the following media: TSA, K5 or K5 with 1 or $500 \mu \mathrm{g} \mathrm{EY} \mathrm{ml}{ }^{-1}$. Further, no Rslike cells could be seen when 50 oil immersion fields of Gram-stained smears of kidneys from each fish were examined, or when kidney smears from 10 of these fish were similarly examined using the indirect fluorescent antibody technique of Bullock \& Stuckey (1975), capable of detecting our Rs and RsR. Evidently the inocu- lated RsR had been killed or sequestered, possibly in other tissues.

All but 3 out of 30 fish inoculated with Rs died of confirmed BKD. Kidneys from 23 of the mortalities contained $99 \pm 19(\mathrm{SD}) \times 10^{9} \mathrm{cfu}^{\mathrm{Rs} \mathrm{g}}{ }^{-1}$ wet wt. The vast number of Rs necessary to kill the host suggests that death depended upon sheer numbers of the pathogen rather than upon production of toxins. However, perhaps the lytic enzymes of the host and/or pathogen (Smith 1964, Goodfellow et al. 1985) could account for the kidney damage reported by Young \& Chapman (1978) and Bruno (1986).

\section{Experiment 2}

The possibility that the avirulence of RsR shown in Experiment 1 was the result of serial passage on laboratory media was examined in a second experiment. Mortalities of fish inoculated with Rs or RsP are shown in Fig. 2. No saline-injected control fish died during the experimental period. Mortality rates in Experiment 2 using Rs were much lower than in Experiment 1 even though inocula used in the second experiment were considerably higher. The lower rate might be attributable to the low post-inoculation rearing temperature and/or the greater size/age of the fish used in this experiment. Nevertheless, mortality rates following inoculation with RsP were even lower than with Rs (comparing inocula of $10^{5}$ and $10^{7} \mathrm{cfu}$ ) and when the experiment was terminated at $208 \mathrm{~d}$ postinoculation (p.i.) only 23 out of 30 RsP-inoculated fish had died, 22 of confirmed BKD. Of the surviving 7 fish, 4 had confirmed infections of Rs but none showed gross signs of the disease. Three fish showed no signs of the infection and, perplexingly, these had been given the highest inoculum. The first group of survivors might be considered carriers whereas the second group might be considered refractory, both conditions possibly related to genetic constitution (Suzumoto et al. 1977).
Fig. 1. Oncorhynchus nerka. Cumulative percent mortality from confirmed BKD (August to January) of sockeye salmon following inoculation with (o) $3.02 \times 10^{6}$, (ㄷ) $3.02 \times 10^{4}$, or (c) $3.02 \times 10^{2}$ cfu of Rs fish $^{-1}$ (Experiment 1). (x) Temperature. (Replicate sockeye salmon similarly inoculated with $3.6 \times 10^{6}, 3.6 \times 10^{4}$ or $3.6 \times 10^{2} \mathrm{cfu}$ of RsR did not die during this experimental period)

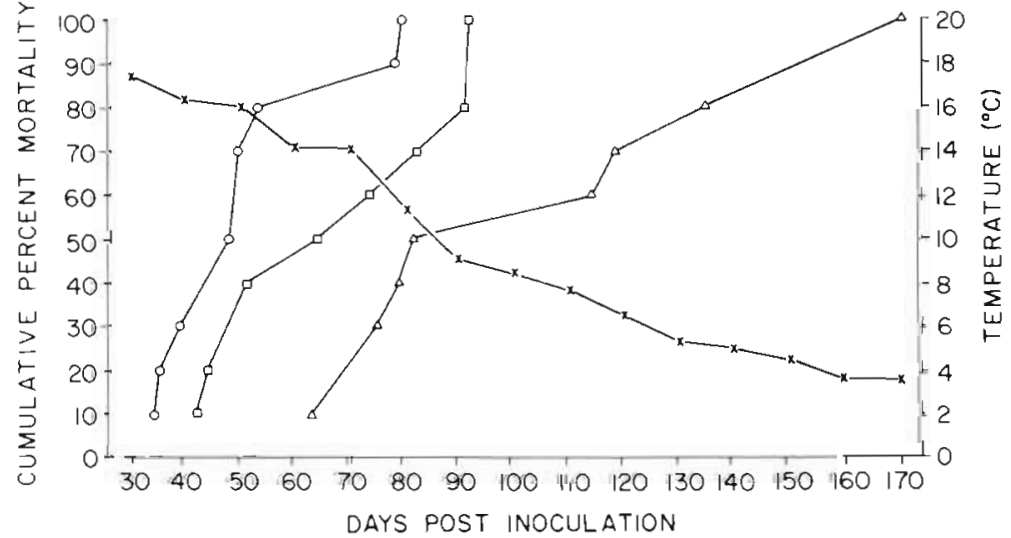




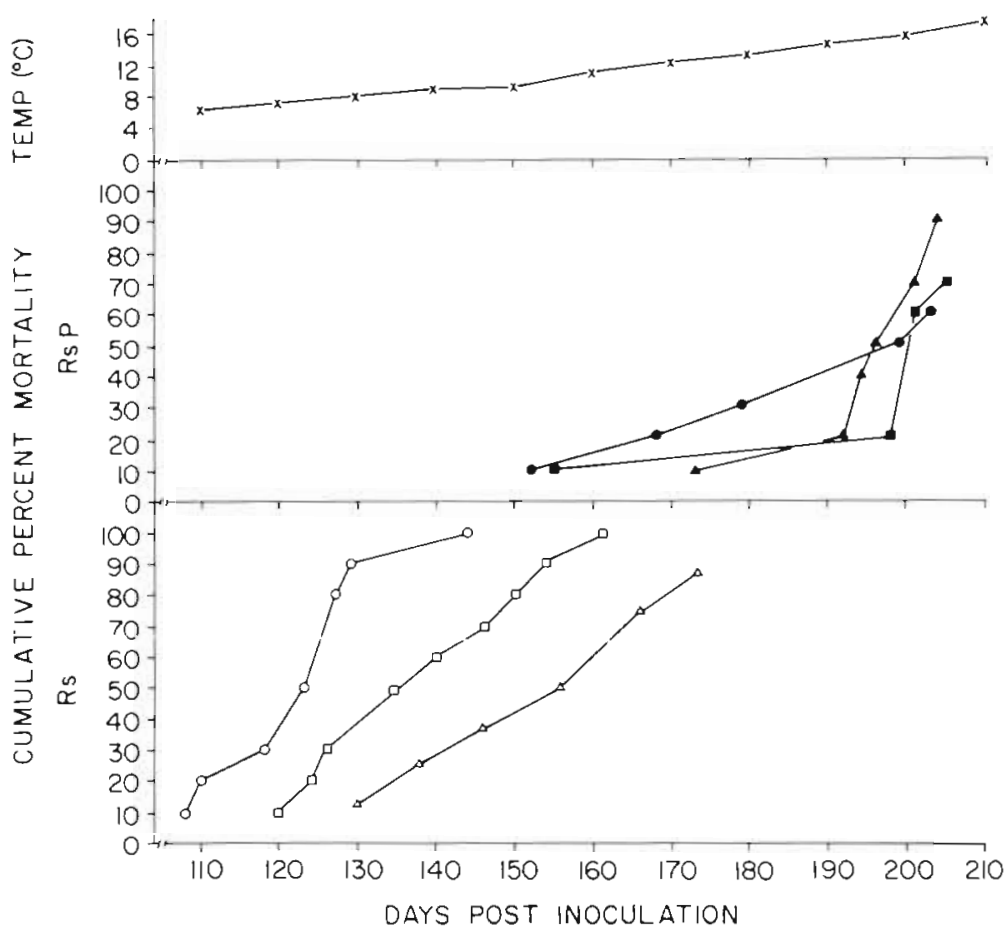

Fig. 2. Oncorhynchus nerka. Cumulative percent mortality from confirmed BKD (December to July) of sockeye salmon following inoculation with (o) $1.2 \times 10^{9}$, (a) $1.2 \times 10^{7}$, or $(\Delta) 1.2 \times 10^{5}$ cfu Rs; or $(\bullet) 5.6 \times 10^{7}$, (-) $5.6 \times 10^{5}$, or (४) $5.6 \times 10^{3}$ cfu RsP (Experiment 2). Ambient temperature of incubation is shown in the upper graph. Experiment terminated at $208 \mathrm{~d}$ p.i. (Replicate sockeye salmon similarly inoculated with $8 \times 10^{9}, 8 \times 10^{7}$, or $8 \times 10^{5}$ cfu RsR did not die during this experimental period)

None of the fish inoculated with RsR (up to $8 \times 10^{9}$ cfu fish ${ }^{-1}$ ) and held in the same type of tank and rearing density as used for Rs- and RsP-inoculated fish succumbed to infection during the $208 \mathrm{~d}$ incubation. However, fish inoculated with $1.6 \times 10^{10} \mathrm{cfu}$ RsR and reared at roughly twice the density began to die at 167 d p.i. At 208 d, $90 \%$ had died, all of confirmed BKD (Fig. 3). These results suggest that the virulence of both RsR and RsP had been reduced by passage on media and that EY might, in addition, have caused selection of a less virulent strain. Typical Rs grew from kidney tissue of 2 mortalities from the RsR inoculated fish (i.e. it grew when plated on $\mathrm{K} 5$ but not when plated on $\mathrm{K} 5$

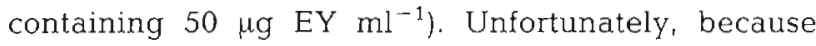
most tissue samples were accidentally destroyed in refrigerated storage, kidneys from only the above 2 fish were available for testing. Therefore, these results sug-

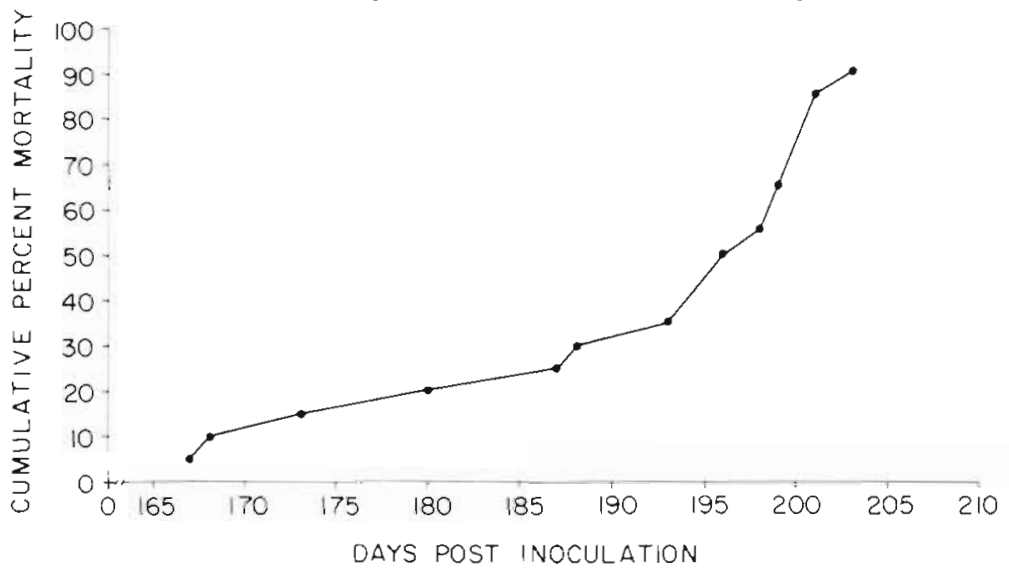

Fig. 3. Oncorhynchus nerka. Cumulative percent mortality from confirmed BKD (December to July) of sockeye salmon inoculated with $1.6 \times 10^{10} \mathrm{cfu}$ of RsR (same cell suspension and water temperature as referred to in Fig. 2) and held at about twice the density used in Experiments 1 and 2 
possibility that resistance of Rs to EY might occur in the field and be associated with transmissible plasmids is of grave concern. Any resistant strains of Rs should be examined for such plasmids. However, if a plasmidless, EY-resistant strain of $R$. salmoninarum were produced as a result of medicating fish stocks (i.e. in vivo), the consequences might be minimal for 2 reasons. First, we have some indication that virulence of a resistant strain might be impaired suggesting that the bacterium may have difficulty under field conditions to colonize the host and invade its tissues, processes that have been well described by Trust (1986). Second, without the selective pressure of the antibiotic, the resistant $R$. salmoninarum may disappear after medication is withdrawn, although this may take some time.

As Austin (1985b) pointed out in his useful guidelines for chemotherapy of fish diseases, 'full dosage must be administered to ensure total inactivation of the pathogen. If even a few cells survive, they may serve as a vehicle for resistance transfer in the aquatic milieu causing further problems'. Survival of resistant cells in vivo may be minimized by using 'combination therapy' which is the simultaneous use of 2 or more non-cross-resistant antimicrobials. This approach to piscine therapy should be considered more frequently because treatment is based on the reasonable assumption that it is highly improbable that a strain of bacterium will produce cells resistant to more than one of these antimicrobials.

Acknowledgements. We thank Dr L. Margolis for his helpful criticism of the manuscript and J. Jensen for statistical analyses.

\section{LITERATURE CITED}

Aoki, T., Kitao, T., Arai T (1977). R plasmids in fish pathogens. In: Mitsuhashi, S., Rosival, L., Krcméry, V. (eds.) Plasmids: medical and theoretical aspects. Avicenum Czechoslovak Medical Press, Prague, p. 39-45

Austin, B. (1985a). Evaluation of antimicrobial compounds for the control of bacterial kidney disease in rainbow trout, Salmo gairdneri Richardson. J. Fish Dis. 8: 209-220

Austin, B. (1985b). Chemotherapy of bacterial fish diseases. In: Ellis, A. E. (ed.) Fish and shellfish pathology. Academic Press, London, p. 19-26

Bell, G. R., Higgs, D. A., Traxler, G. S. (1984). The effect of dietary ascorbate, zinc, and manganese on the development of experimentally induced bacterial kidney disease in sockeye salmon (Oncorhynchus nerka). Aquaculture 36: 293-311

Bruno, D. W. (1986). Histopathology of bacterial kidney disease in laboratory infected rainbow trout, Salmo gairdneri Richardson, and Atlantic salmon, Salmo salar L., with reference to naturally infected fish. J. Fish Dis. 9: 523-537

Bullock, G. L., Leek, S. L. (1986). Use of erythromycin in reducing vertical transmission of bacterial kidney disease. Vet. Human Toxicol. 28 (Suppl. 1): 18-20
Bullock, G. L., Stuckey, H. M. (1975). Fluorescent antibody identification and detection of the Corynebacterium causing kidney disease of salmonids. J. Fish. Res. Bd Can. 32: $2224-2227$

Davies, J., Smith, D. I. (1978) Plasmid-determined resistance to antimicrobial agents. Ann. Rev. Microbiol. 32: 469-518

Evelyn, T. P. T (1977). An improved growt medium for the kidney disease bacterium and some notes on using the medium. Bulletin de l'Office International des Epizooties 87: $511-513$

Evelyn, T. P. T., Ketcheson, J. E., Prosperi-Porta, L. (1986). Use of erythromycin as a means of preventing vertical transmission of Renibacterium salmoninarum. Dis. aquat. Org. 2: $7-11$

Fryer, J. L., Sanders, J. E. (1981). Bacterial kidney disease of salmonid fish. Ann. Rev. Microbiol. 35: 273-298

Goodfellow, M., Embley, T M., Austin, B. (1985). Numerical taxonomy and emended description of Renibacterium salmoninarum. J. gen. Microbiol. 131: 2739-2752

Groman, D. B., Klontz, G. W. (1983). Chemotherapy and prophylaxis of bacterial kidney disease with erythromycin. J. World Mariculture Soc. 14: 226-235

Hastein, T. (1984). Disease problems of salmon farming in Norway. In: McArdle, J. (ed.) The importance of disease in marine fish farming. Aquaculture Technical Bulletin 10 (Ireland), p. 15-30

Klontz, G. W. (1978). Prevention of bacterial kidney disease in adult and juvenile salmonids. In: Proceedings of the Joint 3rd Biennial Fish Health Section and 9th Annual Midwest Fish Disease Workshops, p. 11-14

Miles, A. A., Misra, S. S. (1938). The estimation of the bactericidal power of the blood. J. Hyg. 38: 732-749

Smith, I. W (1964). The occurrence and pathology of Dee disease. Department of Agriculture and Fisheries for Scotland, Freshwater and Salmon Fisheries Research 34: 1-12. (Her Majesty's Stationery Office, Edinburgh)

Stewart-Harris, C. H. Harris, D. M. (eds.) (1982). The control of antibiotic-resistant bacteria. Academic Press, London

Suzomoto, B. K., Schreck, C. B., McIntyre, J. D. (1977). Relative resistances of three transferrin genotypes of coho salmon (Oncorhynchus kisutch) and their hematological responses to bacterial kidney disease. J. Fish. Res. Bd Can. 34: 1-8

Tanaka, K., Teraoka, H., Tamaki, M., Otaka, E., Osawa, S. (1968). Erythromycin-resistant mutant of Escherichia coli with altered ribosomal protein component. Science 162: $576-578$

Toranzo, A. E., Barja, J. L., Colwell, R. R., Hetrick, F. M. (1983). Characterization of plasmids in bacterial fish pathogens. Infect. Immun. 39: 184-192

Trust, T. J. (1986). Pathogenesis of infectious diseases of fish. Ann. Rev. Microbiol. 40: 479-502

Weisblum, B., Demohn, V (1969). Erythromycin-inducible resistance in Staphylococcus aureus: survey of antibiotic classes involved. J. Bacteriol. 98: 447-452

Weisblum, B., Siddhikol, C., Lai, C. J., Demohn, V. (1971). Erythromycin-inducible resistance in Staphylococcus aureus: requirements for induction. J. Bacteriol. 106: 835-847

Wolf, K, Dunbar, C. E. (1959). Tests of 34 therapeutic agents for control of kidney disease in trout. Trans. Am. Fish. Soc. 88: $117-124$

Young, C. L., Chapman, G. B. (1978). Ultrastructural aspects of the causative agent and renal histopathology of bacterial kidney disease in brook trout (Salvelinus fontinalis). J. Fish. Res. Bd Can. 35: 1234-1248 